\title{
Vertical Angulation Alteration Tolerance in the Periapical Radiograph of Maxillary Incisor (An in vitro Study)
}

\author{
Maureen Antolis $^{1}$, Menik Priaminiarti², Bramma Kiswanjaya² \\ ${ }^{1}$ Undergraduate Program, Faculty of Dentistry, Universitas Indonesia, Jakarta 10430, Indonesia \\ ${ }^{2}$ Department of Dentomaxillofacial Radiology, Faculty of Dentistry, Universitas Indonesia, Jakarta 10430, Indonesia \\ Corresponding e-mail to: maureen.antolis@ui.ac.id
}

\begin{abstract}
The prevalence of vertical distortion in the periapical radiograph of the anterior maxillary teeth is quite significant and cingulum is commonly used as the reference of vertical distortion in anterior radiograph. Objective: To evaluate the limit of vertical angulation error that still can be tolerated. Methods: Periapical radiograph with vertical angle $0^{\circ}$ was obtained from 30 maxillary incisors as reference, then the vertical angulation was changed into $-10^{\circ},+10^{\circ}$, $-15^{\circ},+15^{\circ},-20^{\circ}$ and $+20^{\circ}$. Long axis of the teeth was adjusted parallel to the film. Tooth length and cingulum width with vertical angulation alteration was measured and compared to the actual length. All of the measurement was tested using T test. Results: There were no significant differences between all the measurements of tooth length with the alteration in vertical angulation $(p>0.05)$, whereas cingulum width had a significant difference at $+15^{\circ}$ and $-10^{\circ}, p<0.05$. Conclusion: Tooth length in periapical radiograph of maxillary incisor with parallel position is still tolerable until $20^{\circ}$ vertical angle errors. Cingulum width on radiograph with $+15^{\circ}$ vertical angle alteration is significantly narrowed and on radiograph with $-10^{\circ}$ vertical angle alteration is significantly widened.
\end{abstract}

\begin{abstract}
ABSTRAK
Toleransi perubahan angulasi vertikal pada radiografi gigi insisif rahang atas (studi in vitro). Tingkat distorsi vertikal yang cukup besar pada radiograf periapikal gigi anterior rahang atas serta penggunaan lebar singulum sebagai acuan evaluasi distorsi vertikal radiograf gigi anterior. Tujuan: Untuk mengetahui perubahan sudut vertikal yang masih dapat ditoleransi pada radiograf periapikal gigi insisif rahang atas. Metode: Pada 30 gigi insisif rahang atas, dilakukan pembuatan radiograf periapikal sudut vertikal $0^{\circ}$ sebagai acuan standar, selanjutnya dilakukan perubahan sudut vertikal $-10^{\circ},+10^{\circ},-15^{\circ},+15^{\circ},-20^{\circ}$, dan $+20^{\circ}$. Sumbu panjang gigi diatur posisinya supaya sejajar film pada saat dilakukan paparan sinar-X. Kemudian panjang gigi dan lebar singulum pada radiograf dengan perubahan sudut vertikal diukur dan dibandingkan dengan kondisi sebenarnya. Seluruh hasil pengukuran diuji secara statistik dengan menjadi uji T. Hasil: Perbedaan antara panjang gigi klinis dengan panjang gigi radiografik pada seluruh perubahan sudut vertikal terbukti tidak signifikan $(p>0.05)$, sedangkan perubahan lebar singulum signifikan pada sudut $+15^{\circ}$ dan $-10^{\circ}(p<0.05)$. Simpulan: Panjang gigi pada radiograf periapikal gigi insisif rahang atas yang diposisikan sejajar dengan film radiograf masih dapat ditoleransi sampai dengan perubahan sudut vertikal sebesar $20^{\circ}$. Lebar singulum menyempit secara signifikan pada radiograf yang mengalami perubahan sudut $+15^{\circ}$ dan melebar secara signifikan pada radiograf yang mengalami perubahan sudut $-10^{\circ}$.
\end{abstract}

Key words: cingulum, maxillary anterior teeth, periapical radiograph, vertical angulation

\section{PENDAHULUAN}

Pemeriksaan radiografik memegang peranan penting dalam setiap tahap penatalaksanaan kasus kedokteran gigi. Kemampuan pemeriksaan radiografik untuk memproyeksikan area-area yang tidak tampak secara klinis, memperbesar kontribusi informasi diagnostik radiograf sehingga menyebabkan pemeriksaan radiografik kini telah dianggap sebagai pemeriksaan lanjutan dari pemeriksaan klinis dan digunakan pada hampir $80 \%$ penatalaksanaan kasus di bidang kedokteran gigi. ${ }^{1,2}$

Proyeksi periapikal dengan teknik biseksi dan paralel merupakan salah satu teknik pemeriksaan radiografik yang sering dijadikan pilihan utama 
dalam penatalaksanaan kasus. Kedua teknik ini tidak memiliki perbedaan signifikan yang mempengaruhi interpretasi diagnostik kelainan periapikal, namun karena memiliki kemampuan adaptasi pada pasien yang lebih baik, teknik biseksi cukup sering digunakan pada praktik kedokteran gigi. ${ }^{3-5}$ Akan tetapi selain kelebihannya tersebut, teknik biseksi memiliki kelemahan yaitu sering terjadi distorsi akibat kesalahan sudut vertikal dan horisontal. ${ }^{1,2}$

Kesalahan pengaturan sudut vertikal pada teknik biseksi menyebabkan distorsi vertikal yang tampak berupa pemanjangan atau pemendekan ukuran gigi. Pada penatalaksanaan kasus-kasus kedokteran gigi, sering dibutuhkan keakuratan yang tinggi. Hal ini menyebabkan seringkali hasil proyeksi dengan distorsi vertikal perlu dilakukan pengulangan, padahal pengulangan prosedur radiografik bertentangan dengan prinsip ALARA (As Low As Reasonably Achievable) karena akan memperbesar paparan radiasi sinar-X yang diterima oleh pasien. ${ }^{6-8}$

Dalam bidang kedokteran gigi, penelitian mengenai distorsi vertikal pada radiograf periapikal telah banyak dilakukan. Dari hasil penelitian in vitro Gegler et al, ditemukan bahwa perubahan inklinasi gigi sebesar $10^{\circ}$ pada radiograf periapikal belum menyebabkan perubahan dimensi vertikal yang signifikan sehingga pembuatannya tidak perlu diulang. ${ }^{9}$ Selain itu, beberapa penelitian lain membuktikan gigi anterior rahang atas lebih sering mengalami kesalahan sudut vertikal dibandingkan rahang bawah. ${ }^{10-12}$

Berdasarkan penelitian-penelitian yang sudah dilakukan tersebut, diketahui bahwa tingkat kesalahan berupa distorsi vertikal pada radiograf periapikal gigi anterior rahang atas cukup besar,maka perlu dilakukan penelitian untuk mengetahui besar perubahan sudut vertikal pada gigi anterior rahang atas yang masih dapat ditoleransi. ${ }^{11}$ Sampai saat ini acuan evaluasi mutu untuk distorsi vertikal pada gigi anterior yang digunakan adalah berdasarkan perubahan lebar singulum, akan tetapi, singulum sebagai tolok ukur distorsi vertikal ini masih belum pernah diteliti. Oleh karena itu, dalam penelitian ini juga akan diteliti mengenai perubahan lebar singulum pada radiograf periapikal dalam menentukan besarnya distorsi vertikal yang terjadi.

\section{METODE}

Tiga puluh sampel gigi insisif rahang atas diukur panjangnya menggunakan kaliper digital oleh dua orang pengamat masing-masing sebanyak dua kali. Sebelum ditanam menjadi model gigi, bagian singulum gigi insisif diberi tanda dengan kawat orthodontik dan bagian akar gigi dilapisi dengan dental wax $\pm 1 \mathrm{~mm}$.

Proyeksi radiografi periapikal dilakukan pada setiap gigi dengan pesawat sinar-X intraoral Belmont PHOT-X

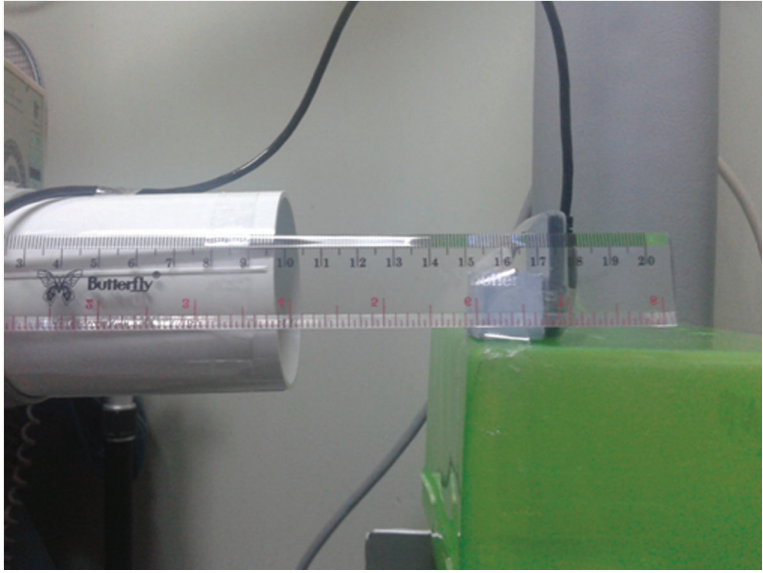

Gambar 1. Radiografi periapikal dengan sudut vertikal 0
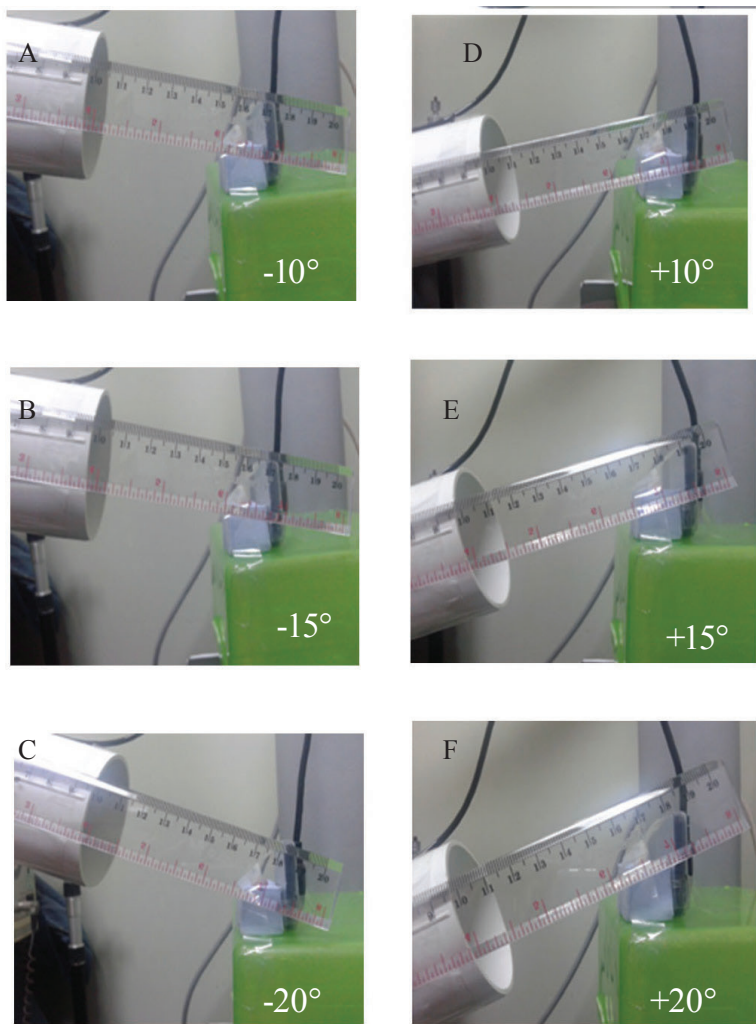

Gambar 2. Prosedur radiografi periapikal dengan perubahan sudut vertikal

II. Sensor intraoral digital Ezsensor Vatech $₫$ direkatkan pada sisi lingual model studi sehingga sejajar dengan sumbu panjang gigi. Sebagai referensi dalam penelitian ini, seluruh gigi diproyeksikan dengan sudut vertikal $0^{\circ}$ (Gambar 1). Kemudian seluruh gigi diproyeksikan lagi dengan perubahan sudut vertikal $-10^{\circ},+10^{\circ},-15^{\circ},+15^{\circ}$, $-20^{\circ}$, dan $+20^{\circ}$ (Gambar 2)

Setelah diperoleh radiograf periapikal seluruh gigi, panjang gigi dan lebar singulum radiografik diukur menggunakan software EasyDent v4 Viewer Vatech ( oleh dua orang pengamat masing-masing sebanyak dua kali (Gambar 3). Kondisi pembacaan di layar monitor komputer dilakukan seoptimal mungkin 


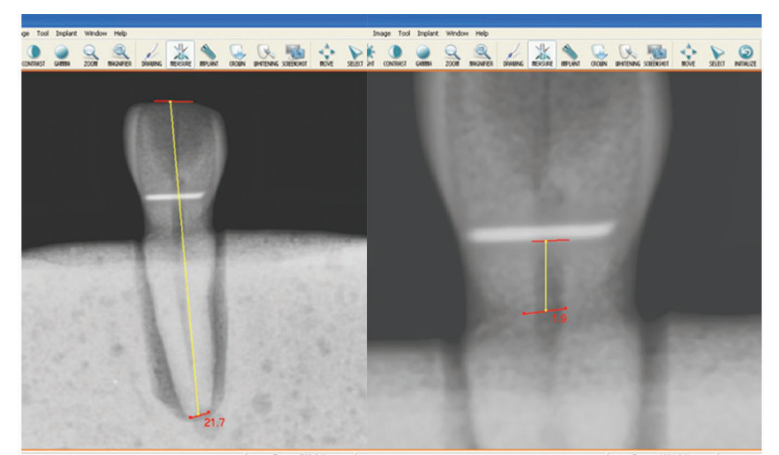

Gambar 3. Pengukuran panjang gigi dan singulum

dengan mengatur brightness, contrast, dan pembesaran radiograf. Kalibrasi pengukuran pada program juga dilakukan untuk menyesuaikan perbandingan pixel radiograf dengan satuan panjang $(\mathrm{mm})$.

Dari hasil pengukuran dua orang pengamat masingmasing sebanyak dua kali, dilakukan uji keandalan hasil penelitian untuk mengukur Technical Error Measurement (TEM). Berdasarkan formula Dahlberg, diketahui reliabilitas intra dan inter observer hasil pengukuran. Data yang akan digunakan untuk diuji dipilih dari nilai TEM yang terkecil. ${ }^{13,14}$

Uji normalitas data Saphiro-wilk yang dilakukan menunjukkan data berdistribusi normal. Kemudian dilakukan uji korelasi Pearson dan uji T antara panjang gigi klinis dan panjang gigi radiograf $0^{\circ}$ untuk menguji validitas metode radiograf periapikal yang digunakan. Dari hasil pengujian, diketahui bahwa terdapat korelasi yang sangat besar $r=0,996$ dan tidak terdapat perbedaan signifikan antara rerata panjang gigi klinis dan kontrol $(p=0.683)$, sehingga dapat disimpulkan bahwa metode penelitian yang digunakan valid. ${ }^{15}$

Uji T parametrik dilakukan dua kali, yaitu untuk menguji signifikansi perbedaan panjang gigi klinis dengan panjang gigi radiograf dengan perubahan sudut $+10^{\circ},+15^{\circ},+20^{\circ},-10^{\circ},-15^{\circ}$, dan $-20^{\circ}$ serta untuk menguji perbedaan lebar singulum radiograf $0^{\circ}$ dengan radiograf $+10^{\circ},+15^{\circ},+20^{\circ},-10^{\circ},-15^{\circ}$, dan $-20^{\circ}$. Uji statistik yang dilakukan memiliki tingkat signifikansi $0,05(p=0,05)$ dan taraf kepercayaan $95 \%(\alpha=0,05) .{ }^{15}$

\section{HASIL}

Hasil uji $\mathrm{T}$ menunjukkan bahwa tidak terdapat perbedaan yang bermakna pada panjang gigi radiograf periapikal sampai dengan perubahan sudut vertikal sebesar $20^{\circ}(p>0,05)$, sedangkan terdapat perbedaan yang bermakna pada lebar singulum dalam arah serviko oklusal pada radiograf dengan sudut vertikal $+15^{\circ}$ dan $-10^{\circ}$. Nilai rerata dan simpang baku panjang gigi dapat dilihat pada Tabel 1. Nilai rerata dan simpang baku lebar singulum dapat dilihat pada Tabel 2 .
Tabel 1. Tabel rerata dan simpang baku panjang gigi

\begin{tabular}{cccc}
\hline & $\begin{array}{c}\text { Jumlah } \\
\text { sampel }\end{array}$ & $\begin{array}{c}\text { Rerata } \pm \text { SB } \\
(\mathbf{m m})\end{array}$ & $\begin{array}{c}\text { Selisih rerata } \\
\text { dengan klinis } \\
(\mathbf{m m})\end{array}$ \\
\hline$-20^{\circ}$ & 30 & $22,67 \pm 1,81$ & 0,37 \\
$-15^{\circ}$ & 30 & $22,58 \pm 1,77$ & 0,28 \\
$-10^{\circ}$ & 30 & $22,56 \pm 1,79$ & 0,26 \\
klinis & 30 & $22,30 \pm 1,71$ & 0,00 \\
$+10^{\circ}$ & 30 & $22,75 \pm 1,73$ & 0,45 \\
$+15^{\circ}$ & 30 & $22,92 \pm 1,76$ & 0,62 \\
$+20^{\circ}$ & 30 & $23,11 \pm 1,71$ & 0,81 \\
Total & 210 & $22,70 \pm 1,74$ & \\
\hline
\end{tabular}

$\mathrm{SB}=$ simpang baku

Tabel 2. Tabel hasil rerata dan simpang baku lebar singulum

\begin{tabular}{cccc}
\hline & $\begin{array}{c}\text { Jumlah } \\
\text { sampel }\end{array}$ & $\begin{array}{c}\text { Rerata } \mathbf{s B} \\
(\mathbf{m m})\end{array}$ & $\begin{array}{c}\text { Selisih rerata } \\
\text { dengan } \mathbf{0}^{\circ} \\
(\mathbf{m m})\end{array}$ \\
\hline$-20^{\circ}$ & 30 & $4,00 \pm 0,82$ & 1,80 \\
$-15^{\circ}$ & 30 & $3,42 \pm 0,65$ & 1,21 \\
$-10^{\circ}$ & 30 & $2,82 \pm 0,71$ & 0,62 \\
$0^{\circ}$ & 30 & $2,20 \pm 0,52$ & 0,00 \\
$+10^{\circ}$ & 30 & $1,97 \pm 0,47$ & 0,23 \\
$+15^{\circ}$ & 30 & $1,77 \pm 0,40$ & 0,44 \\
$+20^{\circ}$ & 30 & $1,61 \pm 0,45$ & 0,60 \\
Total $^{\circ}$ & 210 & $2,54 \pm 1,02$ & \\
\hline
\end{tabular}

$\mathrm{SB}=$ simpang baku

\section{PEMBAHASAN}

Perbedaan rerata dan simpang baku antara panjang gigi klinis dan radiograf yang mengalami perubahan sudut vertikal tidak signifikan secara statistik. Beberapa penelitian yang hasilnya menyerupai dan mendukung hasil penelitian ini adalah penelitian yang mengevaluasi perbedaan panjang kerja sebenarnya dengan panjang kerja pada radiograf digital yang mengalami perubahan sudut vertikal $\left(0^{\circ}, 15^{\circ}, 30^{\circ}\right) .{ }^{16}$ Dari penelitian tersebut, ditemukan bahwa tidak terdapat perbedaan panjang kerja yang signifikan pada perubahan sudut vertikal $15^{\circ}$, namun panjang kerja mengalami pemendekan yang signifikan pada sudut $30^{\circ}$. Penelitian lain juga menemukan bahwa tidak terdapat perubahan panjang gigi yang signifikan pada sudut vertikal $10^{\circ} .9$

Dinyatakan bahwa radiograf digital yang dapat dikalibrasi memberikan hasil yang lebih akurat dibandingkan radiograf konvensional dan radiograf digital yang tidak dapat dikalibrasi. ${ }^{17,18}$ Pengaturan kontras yang dapat diubah juga mempengaruhi hasil pengukuran dari panjang gigi radiograf jika menggunakan radiograf digital. Pengaturan kontras serta pengukuran berkali- 
brasi ini yang diduga meminimalisir distorsi vertikal yang terjadi sehingga menyebabkan perubahan panjang gigi menjadi tidak signifikan.

Besarnya perbedaan panjang gigi berbanding lurus dengan besarnya perubahan sudut vertikal. Hal ini sesuai dengan penelitian yang menemukan bahwa distorsi vertikal yang besar akan cenderung menyebabkan perbedaan panjang kerja yang semakin besar pula. ${ }^{16}$ Akan tetapi pada penelitian ini juga ditemukan bahwa pemanjangan terjadi tidak hanya pada perubahan sudut vertikal negatif tetapi juga pada sudut vertikal positif. Hal ini kemungkinan disebabkan oleh perbedaan posisi gigi, sensor radiograf, dan sinar X yang dilakukan pada penelitian ini dengan posisi teknik biseksi di rongga mulut pasien.

Dari hasil pengolahan data perubahan lebar singulum, diketahui bahwa terdapat perbedaan rerata dan simpang baku yang signifikan pada sudut $+15^{\circ}$ dan $-10^{\circ}$. Perbedaan lebar singulum pada penelitian ini sesuai dengan prinsip pemanjangan dan pemendekan pada distorsi vertikal radiograf periapikal. Data menunjukkan bahwa lebar singulum berbanding terbalik dengan sudut vertikal, yaitu lebar singulum bertambah besar pada perubahan sudut vertikal negatif dan berkurang pada perubahan sudut vertikal positif.,

Perbedaan hasil uji signifikansi rerata panjang gigi dan lebar singulum kemungkinan disebabkan oleh adanya perbedaan ketebalan sampel gigi insisif. Seluruh bagian singulum gigi dapat terproyeksi pada radiograf karena cukup tebal, sedangkan ada bagian permukaan insisal gigi insisif yang tidak terproyeksi karena lebih tipis. Oleh karena itu, distorsi vertikal yang terjadi pada lebar singulum tampak lebih jelas dan perbedaannya signifikan sedangkan distorsi vertikal pada panjang gigi tidak signifikan. ${ }^{2,3}$

Terdapat beberapa faktor yang ikut mempengaruhi hasil penelitian ini. Teknik periapikal yang dilakukan pada penelitian ini berbeda dengan pada teknik periapikal biseksi yang dilakukan di mulut pasien, karena lebar singulum klinis tidak diukur, perubahan lebar singulum dihitung dari perbedaan lebar singulum pada radiograf periapikal yang mengalami distorsi vertikal dengan yang memiliki sudut vertikal $0^{\circ}$. Selain itu, walaupun kedua pengamat memiliki kompetensi dan kesepakatan yang baik pada pengukuran, namun pengalaman yang dimiliki oleh pengamat dalam interpretasi dan pengukuran radiografik tidak sebanyak dokter gigi dan spesialis radiologi kedokteran gigi. Jumlah sampel yang digunakan juga dapat mempengaruhi hasil dari penelitian, sehingga sebaiknya dilakukan penelitian lanjutan dengan jumlah sampel yang lebih besar agar hubungan distorsi vertikal dengan perubahan singulum dapat dianalisis dengan lebih akurat.

\section{SIMPULAN}

Berdasarkan hasil penelitian, dapat disimpulkan bahwa panjang gigi pada radiograf periapikal gigi insisif rahang atas masih dapat ditoleransi sampai dengan perubahan sudut vertikal negatif dan positif $20^{\circ}$. Hasil ini diperoleh dari proyeksi radiograf periapikal gigi insisif rahang atas yang sejajar dengan film radiograf. Selain itu, perubahan lebar singulum pada radiograf periapikal gigi insisif rahang atas melebar secara signifikan pada perubahan sudut vertikal $-10^{\circ}$ dan menyempit secara signifikan pada perubahan sudut vertikal $+15^{\circ}$. Untuk penelitian lanjutan yang sejenis sebaiknya jumlah sampel diperbesar dan lebar singulum klinis diukur sebelumnya agar dapat memperoleh hasil yang lebih akurat. Teknik periapikal yang diaplikasikan juga disesuaikan dengan kondisi struktur anatomis di rongga mulut pasien.

\section{DAFTAR PUSTAKA}

1. Whaites E. Essentials of dental radiography and radio logy. 3rd ed. New York: Churchil Livingstone;2002.

2. White SC, Pharoah MJ. Oral radiology: principles and interpretation. 5th ed. St Louis: Mosby Inc;2004.

3. Forsberg J, Halse A. Periapical radiolucencies as evaluated by bisecting-angle and paralleling radiographic techniques. Int Endod J. 1997; 30:115-23.

4. Ibrahim MF, Aziz MS, Maxood A, Khan WU. Comparison of paralleling and bisecting angle techniques in endodontic working length radiography. Pakistan Oral Dent J. 2003;33:160.

5. Kazzi D, Horner K, Qualtrough AC, MartinezBeneyto Y, Rushton VE. A comparative study of three periapical radiographic techniques for endodontic working length estimation. Int Endod J. 2007;40:52631.

6. Walton RE, Torabinejad M. Endodontics: principles and practice. 3rd ed. Philadelphia: W.B. Saunders Company; 2002.

7. Weiss CM, Weiss A. Principles and practice of implant dentistry. New york: Mosby Inc.; 2001.

8. Williamson GF. Keys to successful intraoral radiography. [Internet]. 2012 [cited 201212 Dec]; Available from: http://www.dentsplylearning. com/contrib/documents/AL_HND_VOJKTJ6081.2010920921359510.pdf.

9. Gegler A, Fontanella V. In vitro evaluation of a method for obtaining periapical radiographs for diagnosis of external apical root resorption. Eur J Orthod. 2008;30:315-9.

10. Felippe MCS. Quality of periapial radiographs taken by undergraduate students during endodontic treatment. Revista Sul-Brasileira de Odontolgia. 2009; 6:63-9.

11. Jayasinghe RD, Weerakoon BS, Perera R, Ediri AWM, Fonseka M, et al. Quality of working length 
radiographs taken and used by dental students during endodontic treatment. Int J Mod Alt Med Res. 2013;1:1-4.

12. Arlenny. Kesalahan sudut vertikal pada pembuatan radiograf periapikal regio anterior oleh mahasiswa profesi FKG UI [skripsi]. Jakarta: Universitas Indonesia; 2011. Indonesian.

13. Harris E, Smith RN. Accounting for measurement error: A critical but often overlooked process. Arch Oral Biol. 2009;54:S107-17.

14. Gore CJ. Physiological tests for elite athletes. 2nd ed: Australian Sports Com; 2013.

15. Dahlan MS. Statistik untuk kedokteran dan kesehatan. 5th ed. Jakarta: Salemba Medika; 2008. Indonesian.

16. Garcia AA, Navarro LF, Castello VU, Laliga RM. Evaluation of a digital radiography to estimate working length. J Endod. 1997;23:363-5.
17. Loushine RJ, Weller RN, Kimbrough WF, Potter BJ. Measurement of endodontic file lengths: calibrated versus uncalibrated digital images. J Endod. 2001; 27:779-81

18. Razi T, Mohammadi A, Ghojazadeh M. Comparison of accuracy of conventional periapical radiography and direct digital subtractions radiography with or without image enhancement in the diagnosis of density changes. J Dent Res Dent Clin Dent Prospects. 2012;6:54-8. 